\title{
Operating limits for beam melting of glass materials
}

\author{
Fabian Eichler ${ }^{1,}$, , Marco Skupin ${ }^{1}$, Laura Katharina Thurn ${ }^{1}$, Susanne Kasch ${ }^{2}$ and Thomas \\ Schmidt ${ }^{2}$ \\ ${ }^{1}$ University of Applied Sciences Aachen, Faculty of Mechanical Engineering and Mechatronics, \\ Goethestr. 1, 52064 Aachen, Germany \\ ${ }^{2}$ Ifw - Günter-Köhler-Institut für Fügetechnik und Werkstoffprüfung GmbH, Otto-Schott-Str.13, \\ 07745 Jena, Germany
}

\begin{abstract}
Laser-based Additive Manufacturing (AM) processes for the use of metals out of the powder bed have been investigated profusely and are prevalent in industry. Although there is a broad field of application, Laser Powder Bed Fusion (LPBF), also known as Selective Laser Melting (SLM) of glass is not fully developed yet. The material properties of glass are significantly different from the investigated metallic material for LPBF so far. As such, the process cannot be transferred, and the parameter limits and the process sequence must be redefined for glass. Starting with the characterization of glass powders, a parameter field is initially confined to investigate the process parameter of different glass powder using LPBFprocess. A feasibility study is carried out to process borosilicate glass powder. The effects of process parameters on the dimensional accuracy of fabricated parts out of borosilicate and hints for the post-processing are analysed and presented in this paper.
\end{abstract}

\section{Introduction}

Laser Powder Bed Fusion (LPBF) is one of the most common processes of Additive Manufacturing (AM) in the industry. It is a laser-based process which is characterized by final products with a detailed accuracy and high density. Based on Computer Aided Design (CAD) data, LPBF-machines can selectively generate a melt pool within the powder bed, creating dense layers. The final product is produced by repetitively applying new powder layers followed by laser melting. Various materials are available, such as carbon steel, stainless steel, cobalt-chromium, aluminium, titanium, nickel-base alloys, gold and more [1]. While there is a lot of research activity for all of these materials, there are only a few publications on LPBF of glass materials. Due to its thermal properties concerning viscosity and heat conduction, glass is not the most suitable material for laser beam melting. Nevertheless, there is a demand for complex shaped parts with high density benefiting from the desired chemical properties of glass materials.

\footnotetext{
* Corresponding author: eichler@fh-aachen.de
} 
Borosilicate has excellent thermal shock resistance (up to $450{ }^{\circ} \mathrm{C}$ ). The material also exhibits high transparency in the visible, near-infrared, and ultraviolet wavelength ranges. It is also highly chemically resistant to acids and alkalis. Additionally, borosilicate is scratch resistant and has a relatively high mechanical strength compared to the other glassy materials. The aforementioned properties of borosilicate ensure that the material is attractive for many industries $[2,3]$.

So far, the fundamental research on AM of glass is reported by different researchers. Klocke et al. studied laser sintering of borosilicate glass including post processing densification in a thermal oven to minimize crack formations. It is reported that porous geometries could be fabricated using this technique [4]. Luo et al. studied the LPBF using a $\mathrm{CO}_{2}$ heat source and extrusion of glass rods for soda-lime glass material. Both approaches showed the potential for depositing optically transparent objects; however, the wire-fed process was reported to be more reliable [5]. Khmyrov et al. investigated SLM processing for quartz glass. In this study, individual lines of quartz powder were melted atop of a quartz substrate. Despite the detachments of lines from the substrate, no crack formations were reported [6].

Fateri et al. has also examined the possibilities of the Nd:YAG LPBF process for soda-lime glass and thereby fabricated 3D objects [7-9]. Although, LPBF of soda-lime was conducted successfully, soda-lime glass material is not resistant to thermal shocks and thereby limited in final fabricated part's application.

Datsiou et al. defined a process window for processing soda-lime quartz glass for processing parts via LPBF. In a feasibility study, parameters for the development of three-dimensional multilayer objects were developed [10].

This study aims to demonstrate the feasibility of processing borosilicate on an industrial AM system using Nd:YAG laser. Section 2 describes the feedstock material, the experimental set-up. Section 3 reports the results, ending up with the conclusion and outlook in chapter 4 .

\section{Experimental Set-up and Description}

In this study, borosilicate powder (according to [11]: "Borosilicatglas 3.3") is used which is produced in a float process and then crushed and sieved down to a narrow size distribution of $125 \mu \mathrm{m}-150 \mu \mathrm{m}$. The powder grain has angular geometries with sharp edges (see in Figure 1). Besides, the powder grain was partially covered by fine particles, which is recognizable in the Scanning Electron Microscopy (SEM) image in Fig. 1 by the white discolorations.

According to the manufacturer (Schott AG) of the material, the thermal conductivity of the powder is $1,2 \mathrm{~W} / \mathrm{m} * \mathrm{~K}$; the transformation temperature is $525^{\circ} \mathrm{C}$, the softening temperature is $820^{\circ} \mathrm{C}$ and the processing temperature is $1270{ }^{\circ} \mathrm{C}$. At a wavelength of $1064 \mathrm{~nm}$, the transmittance of the starting material should be approximately $95 \%$; the remaining transmittance is divided into absorption and reflection. It is important to note that this value refers to a specimen with a thickness of $0,7 \mathrm{~mm}$ and a flat surface. Due to multiple internal reflections at the edges of the powdery material used in the manner of this study, a higher degree of absorption is expected $[2,12]$.

The LPBF system "SLM 50" of the company Realizer used for the test series is equipped with a Nd:YAG laser with a wavelength of $1064 \mathrm{~nm}$ and a maximum laser power of $100 \mathrm{~W}$. With a limited installation space (diameter of the substrate platform: $70 \mathrm{~mm}$ and a height of $80 \mathrm{~mm}$ ), the machine is distributed as a desktop machine for the processing of metals for dental and jewellery applications. Industrial LPBF machines are provided as standard with an Nd:YAG laser, which is particularly suitable for 
processing metals. According to the rules of continuous or linear absorption, processing of glass by a solid-state laser is hardly possible due to the wavelength [13]. The challenge is, therefore, to counteract this rule with the selected initial powder and adapted process parameters.

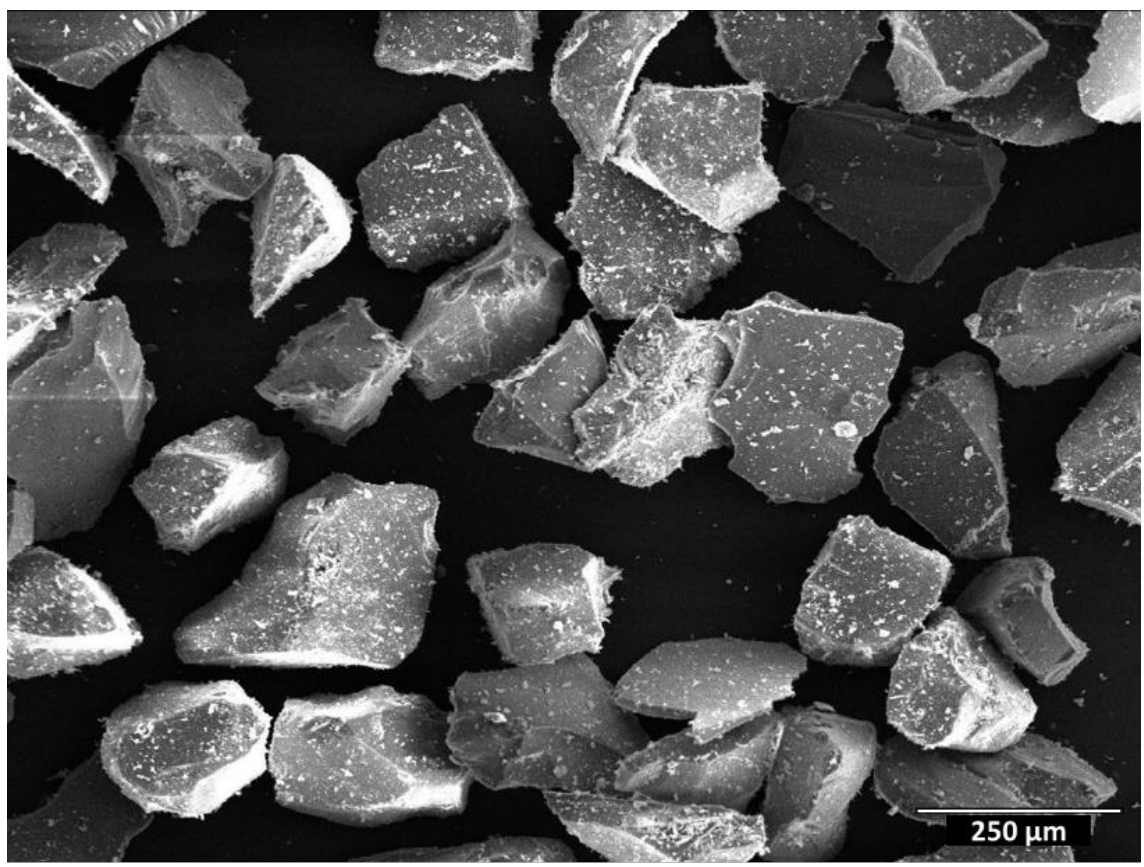

Fig. 1.: SEM image of borosilicate glass powder particles

The substrate plate of the machine can be preheated up to $190{ }^{\circ} \mathrm{C}$. A copper substrate plate is used for the test series within the scope of this paper, which is manually coated with a high-temperature resistant adhesive and a powder layer of borosilicate.

Within the scope of the work, specimens with different process parameters are manufactured. The geometric accuracy is used to characterize the samples. The geometry is verified with a digital microscope "VHX-1000E" from the Keyence company.

The fusion of the powder, in general, is first examined using single-track tests; area and volume tests based on the first tests are used to investigate the heat conduction during the process to achieve complete melting of the powder.

To determine the process segment, the parameters: laser power, scan speed, scan line spacing, and layer thickness are successively changed and adapted. The dependencies of these parameters are represented by the volume energy density ( $\left(E_{V}\right.$ in $\mathrm{J} / \mathrm{mm}^{3}$ ), which is defined according to [14] as followed:

$$
E_{V}=\frac{P_{L}}{V R}=\frac{P_{L}}{v_{s} \cdot h_{s} \cdot l_{7}}
$$

$\mathrm{P}_{\mathrm{L}}=$ laser power $(\mathrm{W}), \mathrm{VR}=$ volume rate $\left(\mathrm{mm}^{3} / \mathrm{s}\right), \mathrm{v}_{\mathrm{s}}=$ scan speed $(\mathrm{mm} / \mathrm{s}), \mathrm{h}_{\mathrm{s}}=$ scan line spacing $(\mathrm{mm}), \mathrm{l}_{\mathrm{z}}=$ layer thickness $(\mathrm{mm})$. 


\section{Results and Discussion}

Investigating the fusion of borosilicate powder, single-track tests are first carried out. The material, which could be described as a thermal and electrical isolator, has a significantly lower heat conduction than steel, which can lead to heat accumulation in the powder bed. Unlike metals, glass materials do not have a fixed solidification temperature at which they are then present in a solid defined phase. Therefore, the rapid cooling rates of the LPBF process are a major disadvantage in this case. [3, 15]

Monolayers and volume bodies are built upon the basis of the gained knowledge from the single-track tests. Due to the material-related characteristics, heat agglomeration plays a particularly significant role. Transferring the individual track parameters to monolayers or solids, the energy input must be drastically reduced. In addition to the energy input, the scan strategy of the laser (the so-called hatch strategy) plays an essential role in the generation of areas and volumes.

Figure 3 shows printed monolayers of borosilicate via LPBF: On the left the hatch strategy "Offset" is shown. The right side shows the "Lines" strategy. With the hatch strategy "Lines" a surface is generated by parallel lines, (see Figure 2 - right). The left side of Figure 2 shows the "Offset" strategy, where the layer is generated by projections of the outer contour offset inwards. The laser scanner unit is programmed in such a way that the laser continuously travels the entire surface of a layer along parallel tracks. In both strategies, the scan line spacing defines the distance between the tracks.

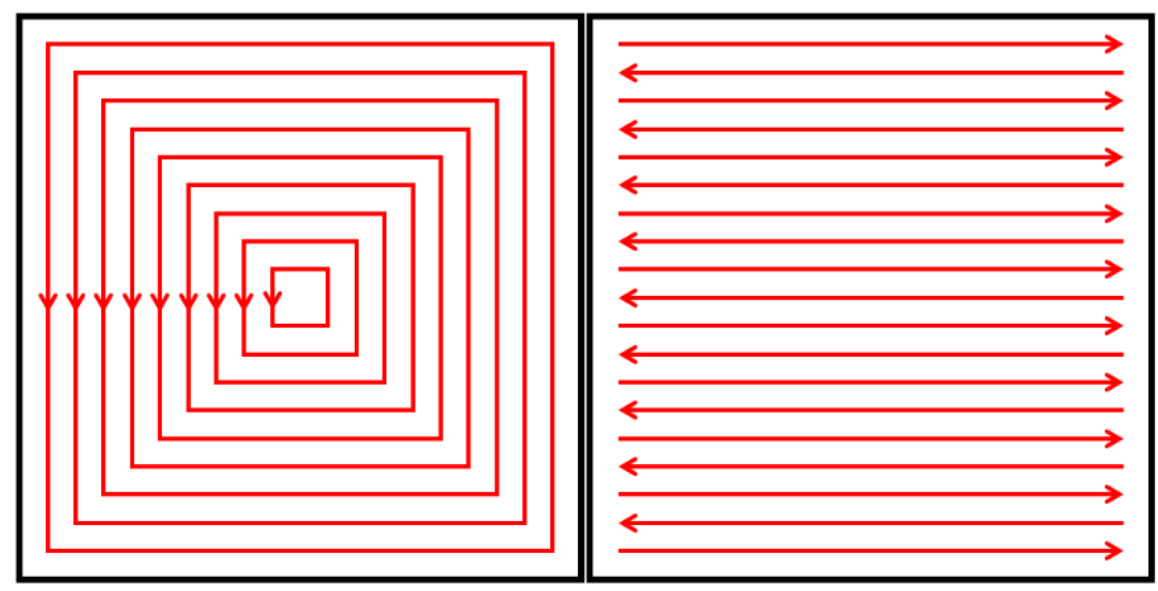

Fig. 2. Different Hatch-Strategies: "Offset" (Left), "Lines" (right)

The test series carried out within the scope of this work show that the hatch strategy "Lines" leads to more comparable results (see Figure 3) - the selected strategy results in more uniform heating of the material of the individual track in process. The previously exposed trace is immediately adjacent to the one currently being generated, and the heat transfer promotes complete fusion of the particles. The "offset" strategy (see Figure 3) clearly shows the effect of heat agglomeration. In outer areas of the monolayer, there is hardly any fusion, while in the center of the layer material evaporates due to overheating.

Based on the results of monolayer tests, the gained knowledge is transferred to multilayer tests with the aim of identifying process or parameter windows for defined solids. For this investigation, a sample geometry in form of a tube (height $10 \mathrm{~mm}$, 
outside diameter $10 \mathrm{~mm}$ and inside diameter $9 \mathrm{~mm}$, i.e. a wall thickness of $0,5 \mathrm{~mm}$ ) is selected. Using different process parameters, geometrical accuracy of the cylindrical products is examined.

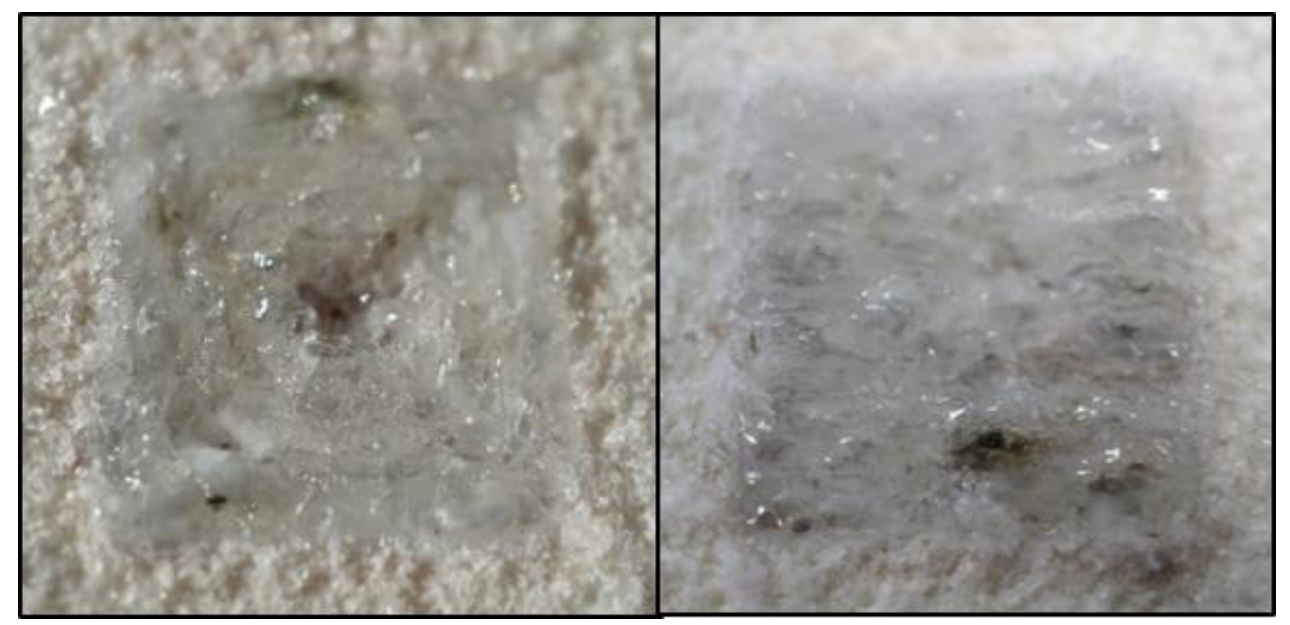

Fig. 3. Production of single layers by "Offset"-Strategy (left) and "Lines"-Strategy (right)

In the test series for parameter determination for the specimen, a constant layer thickness of $200 \mu \mathrm{m}$ is used. This layer thickness corresponds approximately to 1,5 times the powder size of the borosilicate powder examined in this paper as specified by the material contributor. The temperature of the substrate plate is kept constant at $190{ }^{\circ} \mathrm{C}$.

By varying the laser power $\mathrm{P}_{\mathrm{L}}(70 \mathrm{~W}-100 \mathrm{~W})$, the scanning speed $(2,86 \mathrm{~mm} / \mathrm{s}$ to $11,11 \mathrm{~mm} / \mathrm{s})$ and hatch distance $(0,25 \mathrm{~mm}-0,7 \mathrm{~mm})$, specimens are produced and analysed in a wide variety of test series. For a pronounced, complete fusion of the powder, corresponding energy input is necessary (compare chapter 2). This input brings a lot of heat into the "powder cake". Due to the poor thermal conductivity of the feedstock material, the energy introduced can only be dissipated very slowly in the form of heat, which leads to the powder adhering to the already generated component and "sintering" to it. Thus, a conflict of objectives between the complete melting of the component and the geometrical accuracy is concluded. This effect has already been determined with other glass powders in other research work [10, 15].

Figure 4 shows microscopic images of volume bodies with different process parameters, respectively the introduced volume energy density (see equation 1). While with specimen 1 hardly any melted areas can be seen under the microscope, with specimen 4-6 it becomes very clear that powder adheres to the outer walls of the specimen. The microscopic images clearly show that melt traces can only be achieved from a volume energy density of about $200 \mathrm{~J} / \mathrm{mm}^{3}$ to $250 \mathrm{~J} / \mathrm{mm}^{3}$.

In order to counteract the conflicting goals of complete melting of the component and geometrical accuracy, initial considerations and experiments are made on postprocessing strategies for the printed specimens. The surface quality and thus the geometrical accuracy is improved by reheating. The aim is to subsequently fuse the powder adhering within the LPBF process. During the test series, samples are heated up to the softening point of the material via a temperature profile. After keeping it at the softening point and gradually cooling, the specimens are kept at the upper cooling temperature (annealing point). Following these, the surface quilt is improved (see Figure 5). 


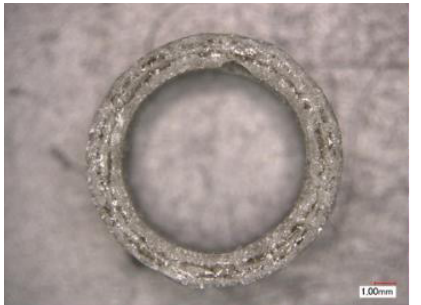

Specimen 1 with $E_{\mathrm{v}}=99,99 \mathrm{~J} / \mathrm{mm}^{3}$

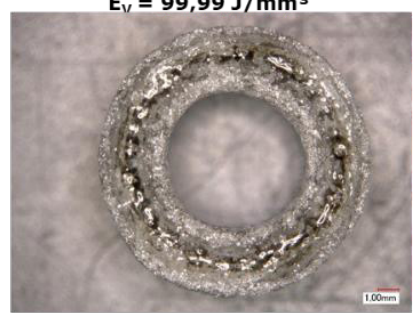

Specimen 4 with

$E_{v}=320,03 \mathrm{~J} / \mathrm{mm}^{3}$

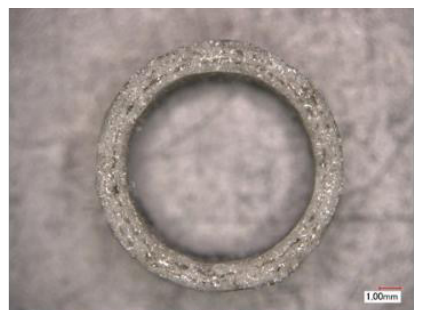

Specimen 2 with $E_{\mathrm{v}}=180,00 \mathrm{~J} / \mathrm{mm}^{3}$

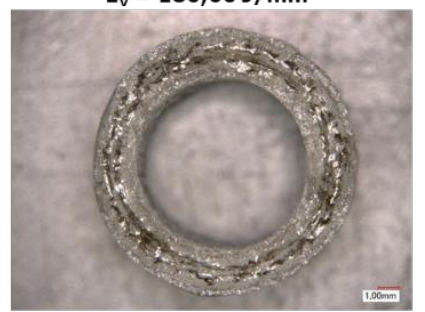

Specimen 5 with

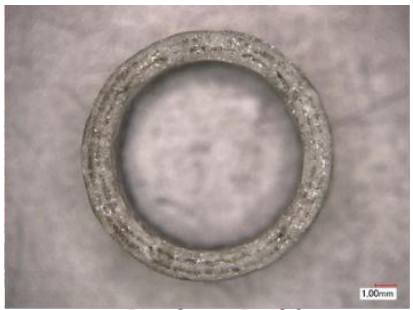

Specimen 3 with $E_{\mathrm{v}}=200,02 \mathrm{~J} / \mathrm{mm}^{3}$

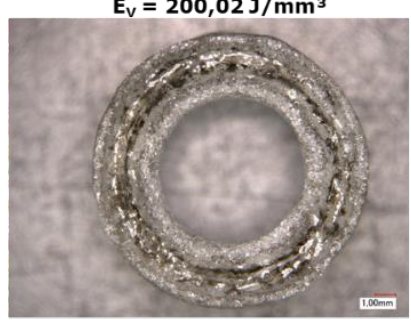

Specimen 6 with $E_{\mathrm{v}}=600,05 \mathrm{~J} / \mathrm{mm}^{3}$

Fig. 4. Different test-specimen - Comparing Energy Input and Accuracy

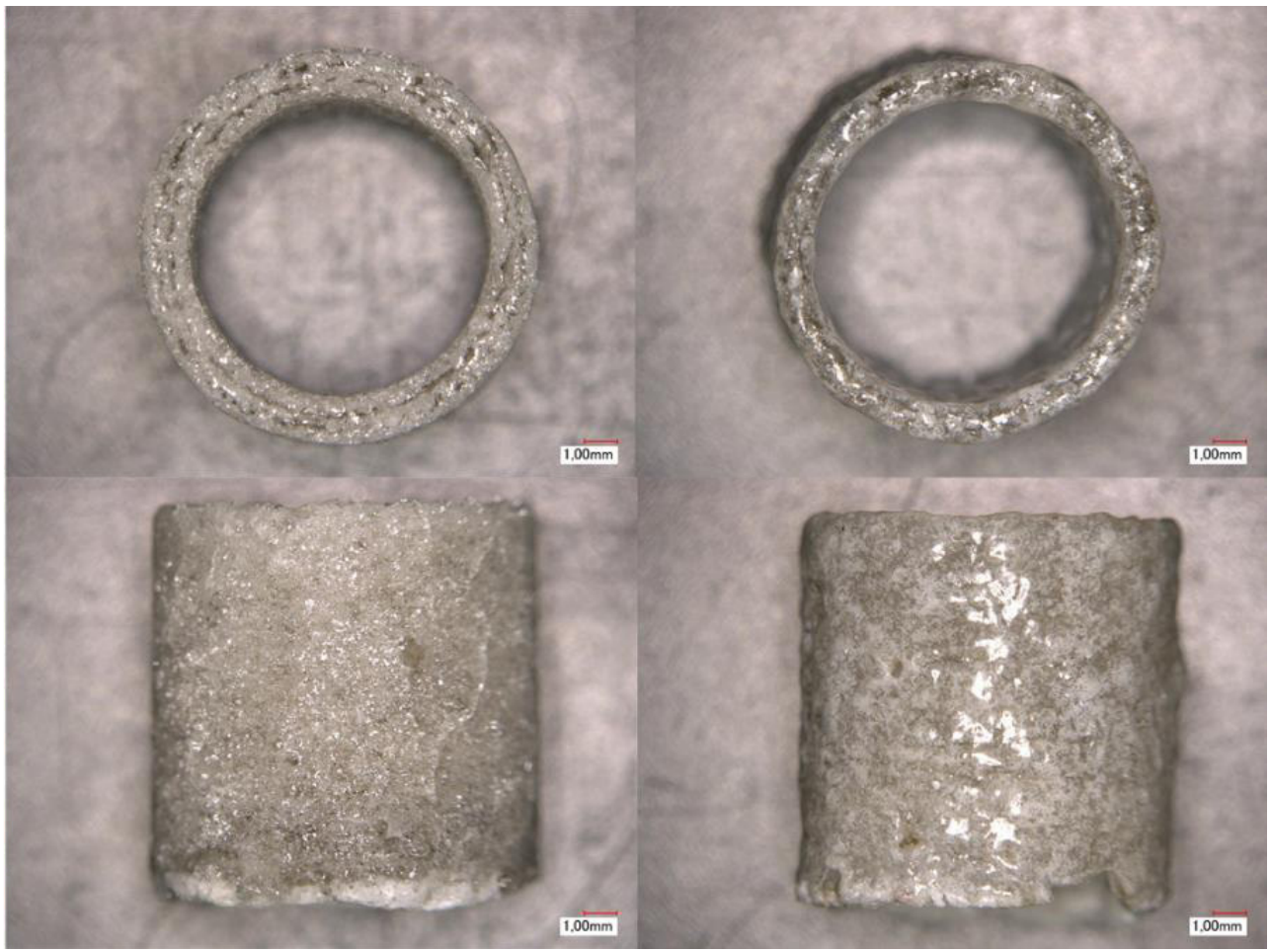

Fig. 5. Specimen $7\left(E_{V}=400,03 \mathrm{~J} / \mathrm{mm}^{3}\right)$ before (left) and after (right) heat treatment

Figure 5 clearly shows that the outer areas with the adhering powder are melted and thus the adhered particles reduced. 


\section{Conclusion}

The work of this paper is aimed at processing borosilicate using LPBF systems which are widely used in the industry. This paper presents a feasibility study on processing borosilicate glass using the LPBF process. By characterizing glass material, investigating the behaviour in single-track tests and transferring the results to monolayers and volume bodies, a basis for further process adaptations is elaborated through basic investigations.

For processing borosilicate using the LPBF process with an Nd:YAG laser, a recommendation for the scanning strategy and a process-reliable energy density range is developed. A suitable post-processing strategy for improving the surface roughness and treatment of adhering powder is developed as part of the study. The knowledge gained serves as a solid basis for further investigation.

\section{References}

1. A. Gebhardt, J. Kessler, L. Thurn: 3D Printing - Understanding Additive Manufacturing, Hanser Publication, Munich (2019)

2. SCHOTT AG N. N.: Borosilicate glass BOROFLOAT® - Product Properties | SCHOTT AG, Mainz, (2019) https://www.schott.com/borofloat/english/attribute/index.html

3. H.A.Schaeffer, R. Langfeld: Werkstoff Glas - Alter Werkstoff mit großer Zukunft (in English: Material glass - old age material with a great future), Springer Verlag Heidelberg (2014)

4. F. Klocke, A. Mc Clung, C. Ader: Direct Laser Sintering of Borosilicate glass, in Solid Freeform Fabrication Symposium, Austin, (2003).

5. J. Luo, H. Pan, E. C. Kinzel: Additive Manufacturing of Glass, Manufacturing Science and Engineering, Bd. 136, Nr. 6 (2015)

6. R. Khmyrov, S. Grigoriev, A. Okunkova und A. Gusarov: On the possibility of selective laser melting of quartz glass, Physics Procedia, Bd. 56, p. 345 - 356 (2014)

7. M. Fateri, A. Gebhardt: Jewelry Fabrication via Selective Laser Melting of Glass, in ASME 12th Biennial Conference on Engineering Systems Design and Analysis, Volume 1: Applied Mechanics; Automotive Systems; Biomedical Biotechnology Engineering, Denmark (2014)

8. M. Fateri, A. Gebhardt: Selective Laser Melting of Soda-Lime Glass Powder, International Journal of Applied Ceramic Technology, Bd. 12, p. 53-61 (2015)

9. M. Fateri: Selective Laser Melting of Glass Powder, Dissertation, Dr. Hut Verlag, Munich (2017)

10. K.C. Datsiou, E. Saleh, F. Spirrett, R. Goodridge, I. Ashcroft, D. Eustice: Additive manufacturing of glass with laser powder bed fusion, American Ceramic Society Journal (2019)

11. DIN ISO 3585, Borosilicate glass 3.3 - Properties, (1999)

12. M. Fateri, A. Gebhardt: Jewelry Fabrication via Selective Laser Melting of Glass, in ASME 12th Biennial Conference on Engineering Systems Design and Analysis, Volume 1: Applied Mechanics; Automotive Systems; Biomedical Biotechnology Engineering, Denmark (2014) 
13. J. Bliedtner, H. Müller, A. Barz: Lasermaterialbearbeitung: Grundlagen - Verfahren Anwendungen - Beispiele (in English: Laser Material Processing: Fundamentals Processes - Applications - Examples), Hanser Publication, Munich, (2013)

14. VDI 3405-2, Additive manufacturing processes, rapid manufacturing - Part 2: Beam melting of metallic parts - Qualification, quality assurance and post processing, (2013)

15. M. Fateri, A. Gebhardt, S. Thuemmler, L. Thurn: Experimental Investigation on Selective Laser Melting of Glass: Physics Procedia, Bd. 56, pp. 357-364, (2014).

16. A. Gebhardt, J. Hötter: Additive Manufacturing - 3D Printing for Prototyping and Manufacturing, Hanser Publication, Munich (2016) 